\title{
A long-term seismic quiescence started 23 years before the 2011 off the Pacific coast of Tohoku Earthquake $(M=9.0)$
}

\author{
Kei Katsumata \\ Institute of Seismology and Volcanology, Hokkaido University, Sapporo 060-0810, Japan \\ (Received April 7, 2011; Revised June 15, 2011; Accepted June 22, 2011; Online published September 27, 2011)
}

\begin{abstract}
I find that a long-term seismic quiescence started 23.4 years before the 2011 off the Pacific coast of Tohoku Earthquake $(M=9.0)$. An earthquake catalog compiled by the Japan Meteorological Agency (JMA) is analyzed. The catalog includes 5770 earthquakes shallower than $60 \mathrm{~km}$ with $M \geq 4.5$. A detailed analysis of the earthquake catalog between 1965 and 2010 using the gridding technique ZMAP shows that the 2011 Tohoku earthquake is preceded by a seismic quiescence anomaly that began in November 1987. The quiescence-anomaly area is located around the deeper edge of the asperity ruptured by the main shock, and the $Z$-value is +4.9 for a time window of $T_{\mathrm{w}}=15$ years, using a sample size of $N=150$ earthquakes. It is suggested that a seismic quiescence which starts more than 20 years before the main shock is common to giant earthquakes $(M \sim 9.0)$ in subduction zones.
\end{abstract} Key words: Seismic quiescence, the 2011 Tohoku earthquake, JMA earthquake catalog, ZMAP, Z-value.

\section{Introduction}

Several significant cases support the hypothesis that seismic quiescence precedes large earthquakes (e.g., Mogi, 1969; Ohtake et al., 1977; Wyss, 1985). Wyss and Habermann (1988) summarized seventeen cases of precursory seismic quiescence to main shocks with magnitudes ranging from $M=4.7$ to 8.0 , and found that (1) the rate of decrease ranges from $45 \%$ to $90 \%$, and (2) the duration of the precursors ranges from 15 to 75 months. Recently, more reliable precursory seismic quiescences have been reported: the Spitak earthquake $(M=7.0)$ in 1988 (Wyss and Martirosyan, 1998), the Landers earthquake $(M=7.5)$ in 1992 (Wiemer and Wyss, 1994), the Hokkaido-Toho-oki earthquake $(M=8.3)$ in 1994 (Katsumata and Kasahara, 1999). On the other hand, little is known whether giant earthquakes $(M \sim 9.0)$ have been preceded by seismic quiescences. Kanamori (1981) pointed out that some giant earthquakes were preceded by seismic quiescences lasting more than 20 years. The purpose of this study is to identify and characterize a long-term seismic quiescence before the 2011 off the Pacific coast of Tohoku Earthquake $(M=9.0)$.

\section{Data}

A temporally-homogeneous earthquake catalog is most important when analyzing temporal changes in seismicity (Habermann, 1987). In this study, the JMA earthquake catalog is used between 1 January, 1965, and 31 December, 2010. Earthquakes shallower than $60 \mathrm{~km}$ along the Kurile and the Japan trenches, excluding earthquakes in the crust beneath the land (Fig. 1), are selected. Firstly, the number of earthquakes versus magnitude for the catalog was

Copyright (C) The Society of Geomagnetism and Earth, Planetary and Space Sciences (SGEPSS); The Seismological Society of Japan; The Volcanological Society of Japan; The Geodetic Society of Japan; The Japanese Society for Planetary Sciences; TERRAPUB.

doi:10.5047/eps.2011.06.033 checked to estimate the degree of completeness, $M_{\mathrm{c}}$. In this study, $M_{\mathrm{c}}$ is defined as the point at which a power law can model $90 \%$, or more, of the frequency-magnitude distribution (Wiemer and Wyss, 2000). $M_{\mathrm{c}}$ is approximately 4.5 from 1965 to 1975 and decreases gradually to 1.0 (Fig. 2(a)). Thus, it is concluded that all earthquakes with $M \geq 4.5$ are located, without fail, between 1965 and 2010. Secondly, temporal changes in $b$-value are checked, which is a parameter in an equation of the frequency of occurrence of earthquakes as a function of magnitude: $\log _{10} N=a-b M$, where $N$ is the cumulative number of earthquakes with magnitude larger than $M$ and $a$ and $b$ are constants. If a large temporal change in $b$-value is observed, the earthquake catalog is probably affected by man-made changes. It was found that the $b$-value ranges almost between 0.9 and 1.0, except for the years between 2003 and 2010 (Fig. 2(a)). Changes in the magnitude were possibly caused by a gradual change in the seismographic network of the JMA after 1997. The amount of the magnitude shift is 0.1 , if the $b$-value between 1997 and 2002 is to be the same as that between 1992 and 1997. Since this magnitude shift is very small, no magnitude correction is applied in this study.

It is concluded that the JMA earthquake catalog is temporally homogeneous between 1965 and 2010 for the magnitude band $M \geq 4.5$, which is the basis of analysis of this study. Clustered events such as aftershocks and earthquake swarms are not removed from the catalog because declustering is a non-unique procedure, which has well-known shortcomings (Zhuang et al., 2002).

\section{Method}

The second important thing for a seismic quiescence analysis is to define spatiotemporal changes in seismicity quantitatively by using statistical parameters. In this study, a gridding technique ZMAP (Wiemer and Wyss, 1994) is 


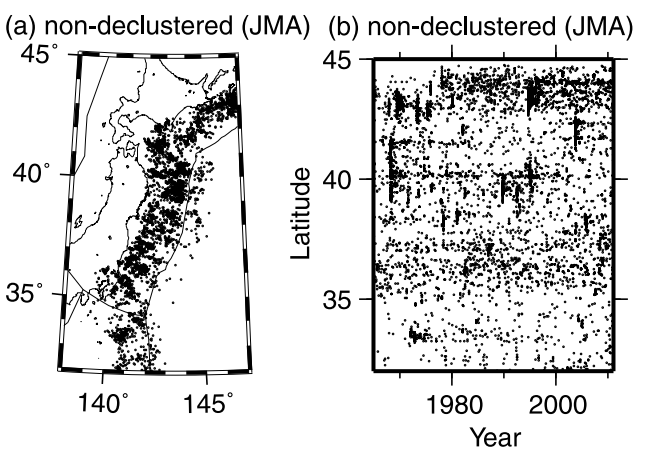

Fig. 1. (a) Epicentral distribution of earthquakes used for calculating $Z$-values in this study along the Kurile and the Japan trenches (1 January 1965-31 December 2010, $M \geq 4.5,0 \leq$ Depth $(\mathrm{km}) \leq 60)$. This is the JMA earthquake catalog including clustered events such as aftershocks and earthquake swarms. (b) Space-time plot of earthquakes shown in (a).

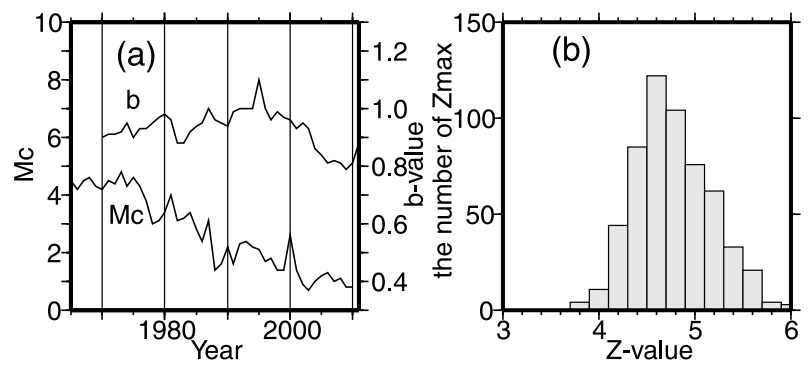

Fig. 2. (a) Temporal change in $b$-value and $M_{\mathrm{c}}$ in the whole study area. $M_{\mathrm{c}}$ is the magnitude of completeness, which is calculated every year. The time window for calculating the $b$-value is five years long and earthquakes with $M \geq 4.5$ are used. For example a $b$-value plotted at the year of 1990 is calculated by using earthquakes which occurred from 1985 to 1990 . (b) Distribution of $Z_{\max }$, obtained by a numerical simulation assuming that earthquakes occur randomly in space and time. 500 synthetic earthquake catalogs are produced by UNIX commands.

used to produce an image of the significance of rate changes in space and time. The study area is divided into grids from $32^{\circ} \mathrm{N}$ to $45^{\circ} \mathrm{N}$ and from $140^{\circ} \mathrm{E}$ to $147^{\circ} \mathrm{E}$ with an interval of $0.05^{\circ}$. A circle is drawn around each node and its radius $r$ is increased until it includes $N=150$ epicenters. The circle defines the resolution circle for a given $N$. The cumulative number of events vs. time is plotted for each node. The cumulative number plot starts at time $t_{0}$ ( 1 January 1965) and ends at time $t_{\mathrm{e}}$ (31 December 2010). A time window is taken starting at $T_{\mathrm{s}}$ and ending at $T_{\mathrm{s}}+T_{\mathrm{w}}$, where $t_{0} \leq T_{\mathrm{s}} \leq T_{\mathrm{s}}+T_{\mathrm{w}} \leq t_{\mathrm{e}}$. I use $T_{\mathrm{w}}=15.0$ years here, and $T_{\mathrm{s}}$ is moved through time, in steps of 0.08 years ( $~ 28$ days). For each window position, the $Z$-value is calculated generating the function LTA defined by Wiemer and Wyss (1994), which measures the significance of the difference between the mean seismicity rate within the window $T_{\mathrm{w}}, R_{\mathrm{w}}$, and the background rate $R_{\mathrm{bg}}$ that is defined here as the mean rate in time period between $t_{0}$ and $t_{\mathrm{e}}$, except for $T_{\mathrm{w}}$. The $Z$-value is defined as

$$
Z=\left(R_{\mathrm{bg}}-R_{\mathrm{w}}\right) /\left(S_{\mathrm{bg}} / n_{\mathrm{bg}}+S_{\mathrm{w}} / n_{\mathrm{w}}\right)^{1 / 2},
$$

where $S$ and $n$ are the variance and number of samples, respectively.

\section{Results}

The $Z$-maps shown in Fig. 3 present typical time slices for the JMA earthquake catalog every four years between $T_{\mathrm{s}}=1976$ and 1996. The declustering process is not applied before the calculation of $Z$-values. In each time slice, only grid points with a radius of resolution circle smaller than $100 \mathrm{~km}$ are selected and colored, which are defined as the effective grids. The number of effective grids is 12815 in each time slice, and there are 575 time slices, thus $12815 \times 575=7368625$ is the total number of effective grid points where $Z$-values are calculated. Among those grid points only 65 nodes have a $Z$-value larger than +4.9 , which is $65 / 7368625 \sim 0.001 \%$. The positive $Z$ values indicate seismic quiescence. I find that the 65 nodes are divided into four quiescence groups: Miyagi, Boso, Sanriku-haruka-oki, and Kurile quiescences.

The Miyagi quiescence starts in 1987.9 , defined by a circle centered at $\left(38.10^{\circ} \mathrm{N}, 141.85^{\circ} \mathrm{E}\right)$ with a radius of $70 \mathrm{~km}$, and characterized by $Z=+4.9$ (Fig. 4(a-c)). Note that "1987.9" does not mean September in 1987 but

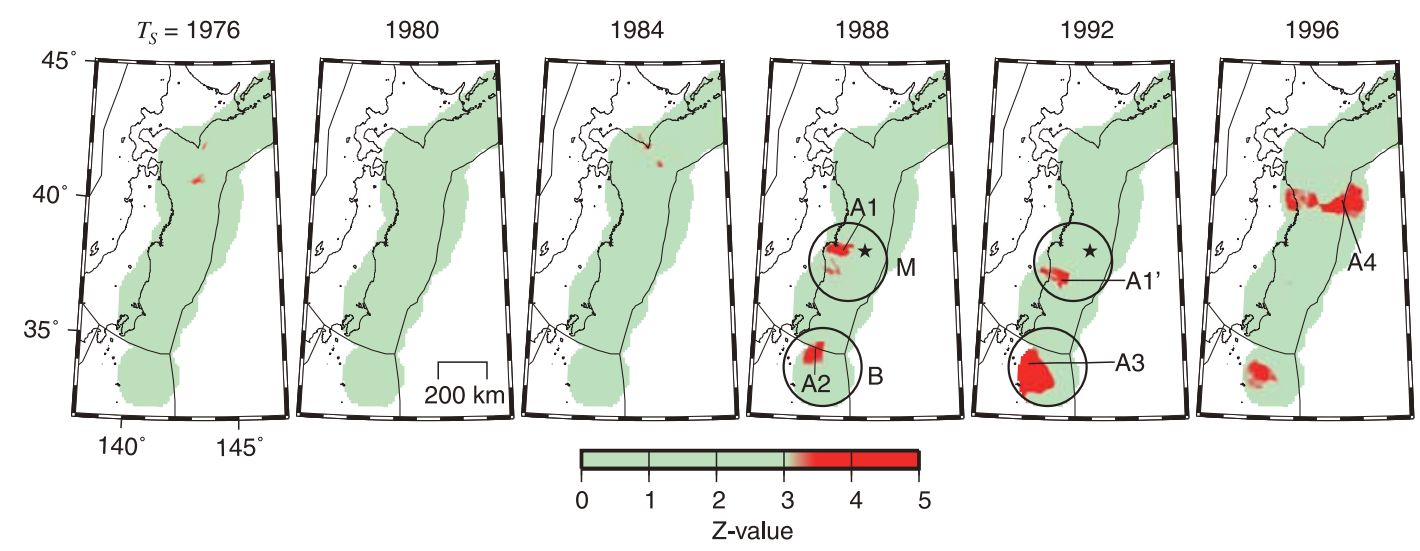

Fig. 3. Time slices of $Z$-value distribution using the JMA non-declustered catalog. A time window starts at $T_{\mathrm{s}}$ and ends at $T_{\mathrm{s}}+T_{\mathrm{w}}$, here $T_{\mathrm{w}}=15$ years. A red color (positive $Z$-value) represents a decrease in the seismicity rate. Circles labeled by $\mathrm{M}$ and B indicate Miyagi and Boso quiescence areas, respectively. A1 and A1' are nodes in the Miyagi quiescence area. A2 and A3 are nodes in the Boso quiescence area. A4 is a node in the Sanriku-haruka-oki quiescence area. 


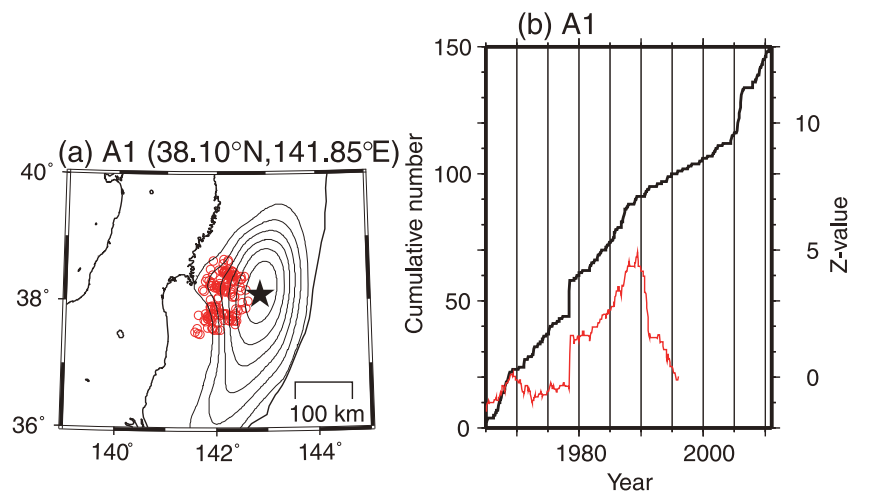

(e) $A 1^{\prime}$
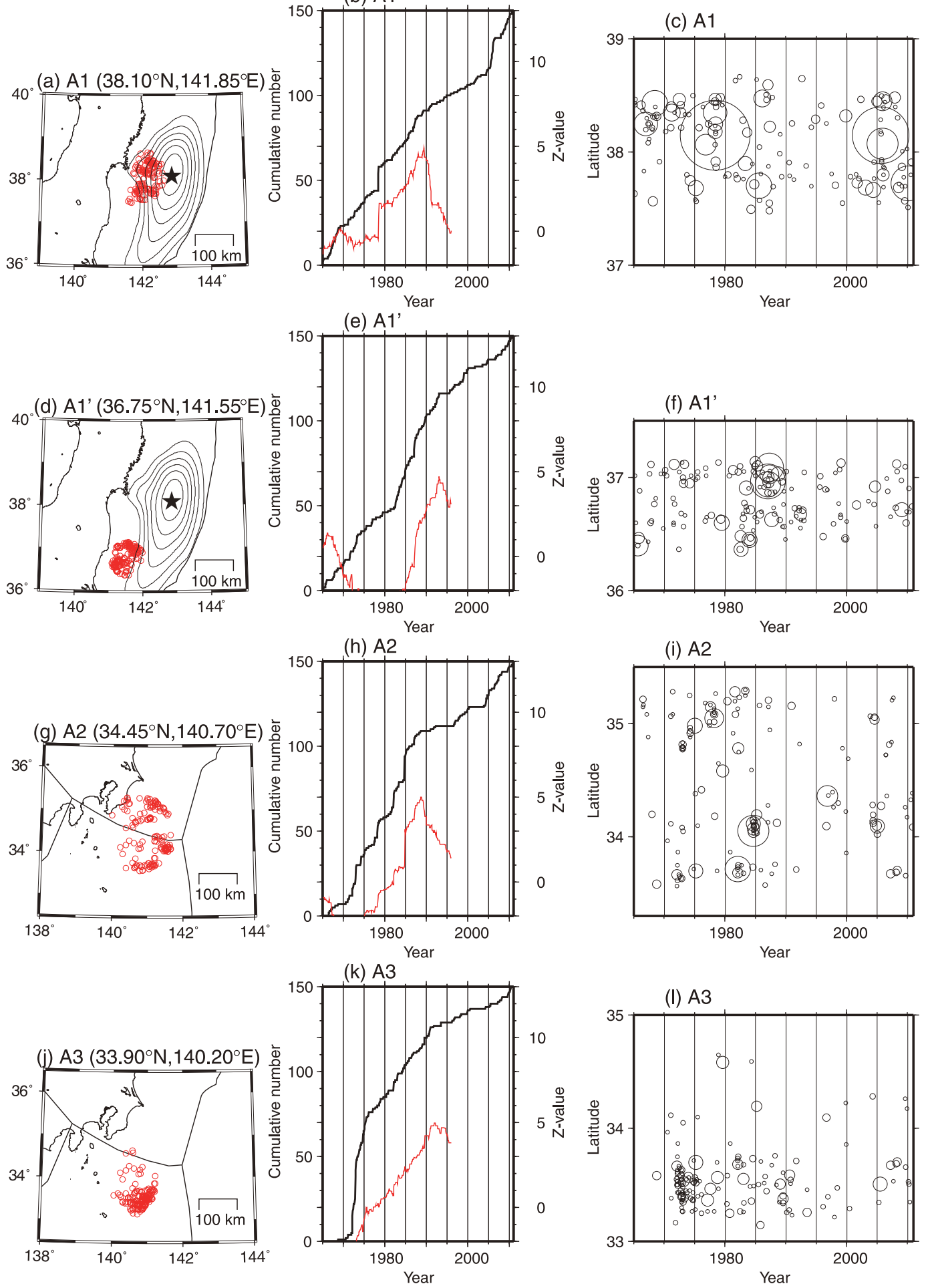

Fig. 4. (a) (d) (g) (j) Red open circles are $N=150$ epicenters sampled around the nodes with the high $Z$-value anomalies detected in Fig. 3. The location of the nodes are shown at the top of each figures, (b) (e) (h) (k) cumulative number curves (black lines) and $Z$-values (red lines) for the sampled epicenters, and (c) (f) (i) (l) space-time plots. A closed star indicates the epicenter of the main shock determined by JMA. The asperity ruptured by the main shock is shown in contour every $4 \mathrm{~m}$ of displacement on the fault (Ozawa et al., 2011).

" $1987+0.9$ ". The seismicity rate decreases by $50 \%$ from 3.0 to 1.5 events/year. In this area, two large earthquakes occurred in 1978 ( $M=7.4)$, which is the Miyagi-kenoki earthquake, and in $2005(M=7.2)$. The two large earthquakes were followed by aftershocks and the cumulative number curve has offsets in 1978 and 2005. However, no large earthquakes with $M \geq 6.0$ occurred in this area around 1988.

The Boso quiescence starts in 1988.6, defined by a circle centered at $\left(34.45^{\circ} \mathrm{N}, 140.70^{\circ} \mathrm{E}\right)$ off the Pacific coast of the Boso peninsula with a radius of $98 \mathrm{~km}$, and $Z=+5.0$ (Fig. 4(g-i)). The seismicity rate decreases by $64 \%$ from 5.0 to 1.8 events/year. No large earthquake with $M \geq 6.0$ occurred in this area around 1988. 
Sanriku-haruka-oki quiescence $\left(40.00^{\circ} \mathrm{N}, 144.15^{\circ} \mathrm{E}\right)$
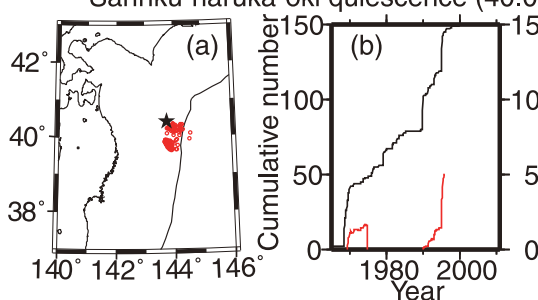

Kurile quiescence $\left(44.55^{\circ} \mathrm{N}, 146.95^{\circ} \mathrm{E}\right)$
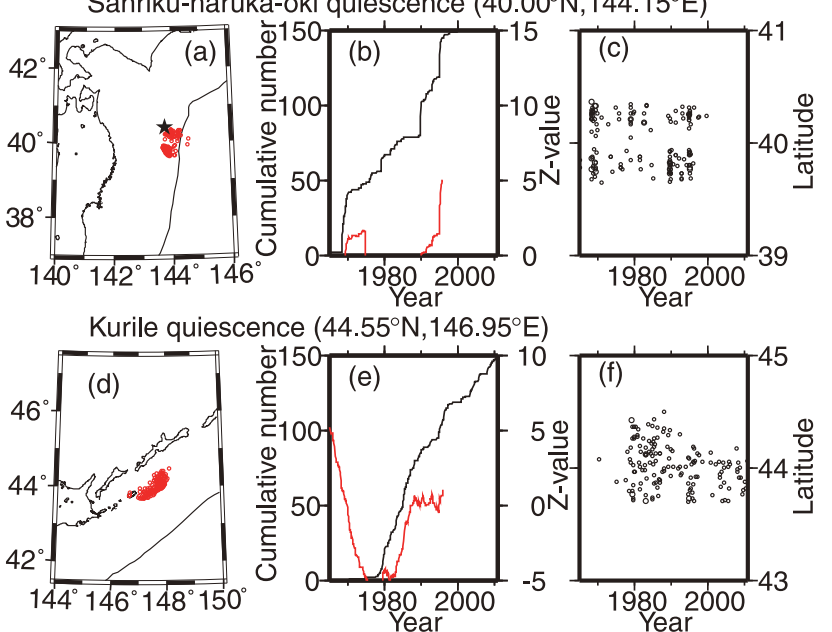

Fig. 5. Sanriku-haruka-oki and Kurile quiescences. A closed star in (a) is the epicenter of the 1994 Sanriku-haruka-oki earthquake. The legends are the same as those of Fig. 4.

Another quiescence is detected near the Boso quiescence, which is defined by a circle at $\left(33.90^{\circ} \mathrm{N}, 140.20^{\circ} \mathrm{E}\right)$ with a radius of $97 \mathrm{~km}$, and $Z=+5.0$ (Fig. $4(\mathrm{j}-1)$ ). In this area, many aftershocks followed two earthquakes larger than $M=7.0$ which occurred in 1972. The decay curve of the aftershocks has two sharp bends in 1975 and 1992. This quiescence is grouped into the Boso quiescence because the two quiescences are located very closely and they start almost simultaneously.

It is clear that the Sanriku-haruka-oki quiescence is caused by aftershocks following a large earthquake with $M=7.6$ in 1994, which is the Sanriku-haruka-oki earthquake (Fig. 5(a-c)). The number of aftershocks decreased quickly after the main shock and a few aftershocks larger than $M=4.5$ occurred after 1996. Thus, an apparent high $Z$-value is found in September 1995.

The Kurile quiescence should be a man-made change (Fig. 5(d-f)). Since the detection capability was improved by the deployment of new seismographs in this area, the seismicity rate increased suddenly after 1977. Therefore, the seismicity rate between 1965 and 1980 is very low compared with that between 1980 and 2010, and thus an apparent high $Z$-value is detected in January 1965.

\section{Discussions}

Based on the analyses above, it is concluded that the Miyagi and the Boso quiescences are true seismic quiescences. Especially the Miyagi quiescence is located near the maximum slip on the asperity ruptured by the 2011 main shock. Although the $Z$-value is smaller than +4.9 , another high $Z$-value anomaly is detected in the circle at $\left(36.75^{\circ} \mathrm{N}\right.$, $141.55^{\circ} \mathrm{E}$ ) with a radius of $44 \mathrm{~km}$, and $Z=+4.7$, which is located around the southern part of the asperity (Fig. 4(df)). The GPS stations near the Miyagi quiescence had been moving toward the east in 2000 (Nishimura, 2011, personal communication). This observation suggests that the Miyagi quiescence is induced by a precursory slow slip.

A declustering process (Reasenberg, 1985) is applied to the JMA catalog and it is found that the Miyagi quiescence is also detected. A numerical simulation is conducted, assuming a random seismicity, in order to estimate the statistical significance of the Miyagi quiescence. As a result, the probability that the long-term seismic quiescence with $Z \geq 4.9$ is observed between 1965 and 2011 (46 years) is $\sim 30 \%$, that is, once every $\sim 150$ years (Fig. 2(b)). Although the Miyagi quiescence detected in this study is not statistically very significant, it would appear to be a longterm precursor to the Tohoku giant earthquake in view of the synchronized change with the crustal deformation.

Previous studies have reported that quiescence started more than 20 years before some giant earthquakes: 32 years for the Kamchatka earthquake $(M=9.0)$ in 1952, 21 years for the Aleutian Islands earthquake $(M=9.1)$ in 1957, and 20 years for the Alaska earthquake $(M=9.2)$ in 1964 (Kelleher and Savino, 1975; Kanamori, 1981). In the case of the Tohoku earthquake, the Miyagi quiescence started 23.4 years before the main shock, which is consistent with previous giant earthquakes.

Acknowledgments. I thank Stefan Wiemer for providing the ZMAP software, and Shinzaburo Ozawa for providing the slip distribution of the main shock. I thank Hiroo Kanamori and an anonymous reviewer for valuable comments to revise the manuscript. GMT-SYSTEM (Wessel and Smith, 1991) is used to map the data.

\section{References}

Habermann, R. E., Man-made changes of seismicity rates, Bull. Seismol. Soc. Am., 77, 141-159, 1987.

Kanamori, H., The nature of seismicity patterns before large earthquakes, in Earthquake Prediction, Maurice Ewing Series, IV, 1-19, AGU, Washington D.C., 1981.

Katsumata, K. and M. Kasahara, Precursory seismic quiescence before the 1994 Kurile earthquake $(\mathrm{Mw}=8.3)$ revealed by three independent seismic catalogs, Pure Appl. Geophys., 155, 443-470, 1999.

Kelleher, J. and J. Savino, Distribution of seismicity before large strike slip and thrust-type earthquakes, J. Geophys. Res., 80, 260-271, 1975.

Mogi, K., Some feature of recent seismic activity in and near Japan (2), Activity before and after great earthquakes, Bull. Earthq. Res. Inst., Tokyo Univ., 47, 395-417, 1969.

Ohtake, M., T. Matsumoto, and G. V. Latham, Seismicity gap near Oaxaca, Southern Mexico as a probable precursor to a large earthquake, Pure Appl. Geophys., 115, 375-386, 1977.

Ozawa, S., T. Nishimura, H. Suito, T. Kobayashi, M. Tobita, and T. Imakiire, Coseismic and postseismic slip of the 2011 magnitude-9 TohokuOki earthquake, Nature, doi:10.1038/nature10227, 2011.

Reasenberg, P. A., Second-order moment of Central California seismicity, 1969-1982, J. Geophys. Res., 90, 5479-5495, 1985.

Wessel, P. and W. H. F. Smith, Free software helps map and display data, Eos Trans. AGU, 72, 445-446, 1991.

Wiemer, S. and M. Wyss, Seismic quiescence before the Landers ( $M=7.5)$ and Big Bare (M=6.5) 1992 earthquakes, Bull. Seismol. Soc. Am., 84, 900-916, 1994.

Wiemer, S. and M. Wyss, Minimum magnitude of completeness in earthquake catalogs: examples from Alaska, the western United States, and Japan, Bull. Seismol. Soc. Am., 90, 859-869, 2000.

Wyss, M., Precursors to large earthquakes, Earthq. Predict. Res., 3, 519 543, 1985.

Wyss, M. and R. E. Habermann, Precursory seismic quiescence, Pure Appl. Geophys., 126, 319-332, 1988.

Wyss, M. and A. H. Martirosyan, Seismic quiescence before the M7, 1988, Spitak earthquake, Armenia, Geophys. J. Int., 134, 329-340, 1998.

Zhuang, J., Y. Ogata, and D. Vere-Jones, Stochastic declustering of spacetime earthquake occurrences, J. Am. Stat. Assoc., 97(458), 369-380, 2002.

K. Katsumata (e-mail: kkatsu@mail.sci.hokudai.ac.jp) 